\title{
Metal protein attenuating compounds for the treatment of Alzheimer's dementia (Review)
}

\author{
Sampson EL, Jenagaratnam L, McShane R
}

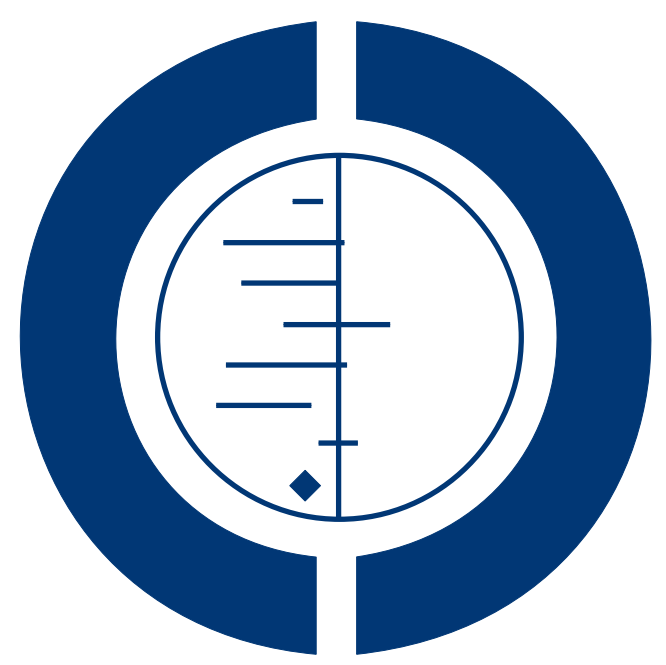

\section{THE COCHRANE COLLABORATION $^{\circledR}$}

This is a reprint of a Cochrane review, prepared and maintained by The Cochrane Collaboration and published in The Cochrane Library 2014, Issue 2

http://www.thecochranelibrary.com

\section{WILEY}

Metal protein attenuating compounds for the treatment of Alzheimer's dementia (Review)

Copyright $\odot 2014$ The Cochrane Collaboration. Published by John Wiley \& Sons, Ltd. 
TABLE OF CONTENTS

HEADER . . . . . . . . . . . . . . . . . . . . . . . . . . . . . . . . . . 1

ABSTRACT . . . . . . . . . . . . . . . . . . . . . . . . . . . . . . . . . . . . . . . . . . . .

PLAIN LANGUAGE SUMMARY . . . . . . . . . . . . . . . . . . . . . . . . . . . . . . . . . . . 2

BACKGROUND . . . . . . . . . . . . . . . . . . . . . . . . . . . . . . . . . . . . . . . . .

OBJECTIVES . . . . . . . . . . . . . . . . . . . . . . . . . . . . . . . . . . . . . . . . . . . .

METHODS . . . . . . . . . . . . . . . . . . . . . . . . . . . . . . . . . . . . . . .

RESULTS . . . . . . . . . . . . . . . . . . . . . . . . . . . . . . . . . . . . . 5

DISCUSSION . . . . . . . . . . . . . . . . . . . . . . . . . . . . . . . . . . . . . 8

AUTHORS' CONCLUSIONS . . . . . . . . . . . . . . . . . . . . . . . . . . . . . . . . . . . . . . . . . .

ACKNOWLEDGEMENTS . . . . . . . . . . . . . . . . . . . . . . . . . . . . . . . . . 9

REFERENCES . . . . . . . . . . . . . . . . . . . . . . . . . . . . . . . . . . . . . . . 9

CHARACTERISTICS OF STUDIES . . . . . . . . . . . . . . . . . . . . . . . . . . . . . . . . . . . . .

DATA AND ANALYSES . . . . . . . . . . . . . . . . . . . . . . . . . . . . . . . . . . . . . . . . . . . . . . . . . . .

Analysis 1.1. Comparison 1 Change ADAS-Cog after 36 weeks clioquinol or placebo, Outcome 1 Change in ADASCog at 36 weeks. . . . . . . . . . . . . . . . . . . . . . . . . . . 14

APPENDICES . . . . . . . . . . . . . . . . . . . . . . . . . . . . . . . . . . . . . . 14

WHAT'S NEW . . . . . . . . . . . . . . . . . . . . . . . . . . . . . . . . . . . . . . . . . . . . .

HISTORY . . . . . . . . . . . . . . . . . . . . . . . . . . . . . . . . . . . . . . . 19

CONTRIBUTIONS OF AUTHORS . . . . . . . . . . . . . . . . . . . . . . . . . . . . . . . . . . . . . . . . .

DECLARATIONS OF INTEREST . . . . . . . . . . . . . . . . . . . . . . . . . . . . . . . . . . . . . . . . .

SOURCES OF SUPPORT . . . . . . . . . . . . . . . . . . . . . . . . . . . . . . . . . . . . . . . . . . . . . .

INDEX TERMS . . . . . . . . . . . . . . . . . . . . . . . . . . . . . . . . . . . . 21

Metal protein attenuating compounds for the treatment of Alzheimer's dementia (Review)

Copyright @ 2014 The Cochrane Collaboration. Published by John Wiley \& Sons, Ltd. 


\title{
[Intervention Review]
}

\section{Metal protein attenuating compounds for the treatment of Alzheimer's dementia}

\author{
Elizabeth L Sampson ${ }^{1}$, Lydia Jenagaratnam ${ }^{2}$, Rupert McShane ${ }^{3}$ \\ ${ }^{1}$ Marie Curie Palliative Care Research Unit, University College, London, UK. ${ }^{2}$ The Fulbrook Centre, Churchill Hospital, Oxford, \\ UK. ${ }^{3}$ Radcliffe Department of Medicine, University of Oxford, Oxford, UK \\ Contact address: Elizabeth L Sampson, Marie Curie Palliative Care Research Unit, University College, 67-73 Riding House Street, \\ London, W1W 7EJ, UK. e.sampson@ucl.ac.uk. e.sampson@medsch.ucl.ac.uk.
}

Editorial group: Cochrane Dementia and Cognitive Improvement Group.

Publication status and date: Edited (no change to conclusions), published in Issue 2, 2014.

Review content assessed as up-to-date: 9 February 2012.

Citation: Sampson EL, Jenagaratnam L, McShane R. Metal protein attenuating compounds for the treatment of Alzheimer's dementia. Cochrane Database of Systematic Reviews 2014, Issue 2. Art. No.: CD005380. DOI: 10.1002/14651858.CD005380.pub5.

Copyright (C) 2014 The Cochrane Collaboration. Published by John Wiley \& Sons, Ltd.

\begin{abstract}
A B S T R A C T
Background

Alzheimer's dementia (AD) may be caused by the formation of extracellular senile plaques comprised of beta-amyloid (Aß). In vitro and mouse model studies have demonstrated that metal protein attenuating compounds (MPACs) promote the solubilisation and clearance of $A ß$.
\end{abstract}

\section{Objectives}

To evaluate the efficacy of metal protein attenuating compounds (MPACs) for the treatment of cognitive impairment due to Alzheimer's dementia.

\section{Search methods}

We searched ALOIS, the Cochrane Dementia and Cognitive Improvement Group Specialized Register, on 29 July 2010 using the terms: Clioquinol OR PBT1 OR PBT2 OR “metal protein” OR MPACS OR MPAC.

\section{Selection criteria}

Randomised double-blind trials in which treatment with an MPAC was administered to participants with Alzheimer's dementia in a parallel group comparison with placebo were included.

\section{Data collection and analysis}

Three review authors (RM, LJ, ELS) independently assessed the quality of trials according to the Cochrane Handbook for Systematic Reviews of Interventions.

The primary outcome measure of interest was cognitive function (as measured by psychometric tests). The secondary outcome measures of interest were in the following areas: quality of life, functional performance, effect on carer, biomarkers, safety and adverse effects, and death.

Metal protein attenuating compounds for the treatment of Alzheimer's dementia (Review)

Copyright @ 2014 The Cochrane Collaboration. Published by John Wiley \& Sons, Ltd. 


\section{Main results}

Two MPAC trials were identified. One trial compared clioquinol (PBT1) with placebo in 36 patients and 32 had sufficient data for per protocol analysis. There was no statistically significant difference in cognition (as measured on the Alzheimer's Disease Assessment Scale - Cognition (ADAS-Cog)) between the active treatment and placebo groups at 36 weeks. The difference in mean change from baseline ADAS-Cog score in the clioquinol arm compared with the placebo arm at weeks 24 and 36 was a difference of 7.37 (95\% confidence interval (CI) 1.51 to 13.24 ) and 6.36 (95\% CI -0.50 to 13.23), respectively. There was no significant impact on noncognitive symptoms or clinical global impression. One participant in the active treatment group developed neurological symptoms (impaired visual acuity and colour vision) which resolved on cessation of treatment and were possibly attributable to the drug.

In the second trial a successor compound, PBT2, was compared with placebo in 78 participants with mild Alzheimer's dementia; all were included in the intention-to-treat analysis. There was no significant difference in the Neuropsychological Test Battery (NTB) composite or memory between placebo and PBT2 in the least squares mean change from baseline at week 12 . However, two executive function component tests of the NTB showed significant improvement over placebo in the PBT2 250 mg group from baseline to week 12: category fluency test $(2.8$ words, $95 \%$ CI 0.1 to $5.4 ; \mathrm{P}=0.041)$ and trail making part $\mathrm{B}(-48.0 \mathrm{~s}, 95 \% \mathrm{CI}-83.0$ to $-13.0 ; \mathrm{P}=0.009)$. In the executive factor $Z$ score, the difference in least squares mean change from baseline at week 12 for PBT2 $250 \mathrm{mg}$ compared with placebo was $0.27(0.01$ to $0.53 ; \mathrm{p}=0.042)$. There was no significant effect on cognition on Mini-Mental State Examination (MMSE) or ADAS-Cog scales. PBT2 had a favourable safety profile.

\section{Authors' conclusions}

There is an absence of evidence as to whether clioquinol (PBT1) has any positive clinical benefit for patients with AD, or whether the drug is safe. We have some concerns about the quality of the study methodology; there was an imbalance in treatment and control groups after randomisation (participants in the active treatment group had a higher mean pre-morbid IQ) and the secondary analyses of results stratified by baseline dementia severity. The planned phase III trial of PBT1 has been abandoned and this compound has been withdrawn from development. The second trial of PBT2 was more rigorously conducted and showed that after 12 weeks this compound appeared to be safe and well tolerated in people with mild Alzheimer's dementia. Larger trials are now required to demonstrate cognitive efficacy.

\section{PLAIN LANGUAGE SUMMARY}

\section{There is no evidence that MPACs (PBT1 or PBT2) are of benefit in Alzheimer's dementia}

The protein amyloid- $\beta(A ß)$ is strongly implicated in the development of Alzheimer's dementia, where it aggregates in clumps causing damage and death of brain cells. This clumping is encouraged by copper and zinc (metal ions) in the brain. Metal protein attenuating compounds (MPACS) bind strongly to copper and zinc (this is known as chelation), both preventing the clumping together of Aß and promoting processes which may cause it to dissolve and so be cleared from brain cells. Therefore MPACS may be a potential therapy for Alzheimer's dementia. Two different types of MPAC have been used in clinical trials and the drugs are known as PBT1 and PBT2. The trial of PBT1 compared with placebo (in 36 patients) showed no statistically significant difference in cognition or memory between the active treatment and placebo groups at 36 weeks. We therefore conclude that there is no current evidence that treatment with clioquinol (PBT1) has any significant effect on cognition and in particular memory (as measured by the ADAS-Cog scale) in patients with Alzheimer's dementia. This drug has now been withdrawn from development. The trial of PBT2 showed it was safe after 12 weeks of treatment but demonstrated no overall significant effect on cognition or memory.

\section{B A C K G R O U N D}

Alzheimer's dementia $(\mathrm{AD})$ is a progressive brain disease characterised by impairment of memory and multiple cognitive domains (including language, praxis and executive functions). The prevalence of $\mathrm{AD}$ increases with age, affecting $4.3 \%$ of those aged 75 to 79 years and rising to $28.5 \%$ of those over 90 years (Brookmeyer 
1998). The characteristic neuropathological features are extracellular senile plaques (comprised of insoluble aggregated amyloid fibrils), intracellular neurofibrillary tangles, frequent granulovacuolar degeneration and loss of cortical neurons. These individual components all occur to some extent in normal ageing. However, the key distinction is that changes in $\mathrm{AD}$ are more numerous and more widely distributed.

The amyloid hypothesis suggests that intracellular soluble oligomers of beta-amyloid (Aß) trigger a cascade of events leading to oxidative stress and adverse metabolic conditions within neurones (Wirths 2004). The deposition of $A ß$ plaques in the neocortex occurs after this and is a key pathological finding in $\mathrm{AD}$. Metals (copper, iron and zinc) are concentrated in and around amyloid plaques in AD brains (Atwood 2002). There is evidence that these metals interact with $A ß$, catalysing the production of hydrogen peroxide. This contributes to oxidative stress, generating Aß fibrils that have a high tendency to aggregate, are toxic and are resistant to clearance (Bush 1994; Bush 2003).

Metal protein attenuating compounds (MPACs) differ from traditional chelators. They have only moderate affinity for metal ions and are capable of crossing the blood-brain barrier. Rather than systemic binding and removal of metals from tissues, they correct abnormal metal interactions and have subtle effects on metal homeostasis, inhibiting $\mathrm{Zn}^{2+}$ and $\mathrm{Cu}^{2+}$ induced oligermisation of $A ß$. This promotes the solubilisation (and clearance) of $A ß$ and inhibits redox reactions that generate neurotoxic hydrogen peroxide. Consequently MPACs might provide a viable therapeutic strategy for slowing or preventing the progression of Alzheimer's dementia (Bush 2003).

Clioquinol (5-chloro-7-iodo-8-hydroxyquinolinol) (PBT1) is an MPAC. It is an anti-bacterial and anti-fungal agent. Topical clioquinol preparations are still prescribed to treat skin infections. Clioquinol was extensively used in the past as an anti-infective, especially for diarrhoea. It was withdrawn from oral use in 1970 after being associated with a Japanese epidemic of neurotoxicity, subacute myelo-optic neuropathy (SMON) (Cherny 2001; Yassin 2000). This syndrome is characterised by subacute visual changes (optic neuritis) and upper and lower motor neurone lower limb signs. The physical signs of SMON are similar to those of subacute combined degeneration of the cord secondary to vitamin B12 deficiency. It has been suggested that the Japanese population was endemically deficient in vitamin B12, as a consequence of their diet following the Second World War, and that this predisposed them to SMON (Cherny 2001). Therefore, in people treated with clioquinol SMON might be avoided by giving vitamin B12.

Clioquinol is hydrophobic and crosses the blood-brain barrier. It binds to the $A ß$ metal-ion complex and may act by disaggregating collections of $A ß$ and copper, in effect 'dissolving' accumulations of $A ß$ (Bush 2003). One pilot phase II study reported no significant effect of clioquinol versus placebo on the rate of cognitive decline in a cohort of patients with AD (Ritchie 2003). Furthermore, the planned phase III trial of clioquinol (PBT1) was abandoned and this compound has been withdrawn from development (Prana 2005).

A further compound, PBT2, has been tested in a phase IIa randomised, double-blind, placebo-controlled trial (Lannfelt 2008). This MPAC is a second generation $8-\mathrm{OH}$ quinoline, which in animal models was found to target $A ß$ oligomers (Adlard 2008).

\section{O B J E C T I VES}

\section{Primary objective}

To evaluate the efficacy of MPACs for the treatment of cognitive impairment due to Alzheimer's dementia (AD).

\section{Secondary objectives}

To review the quality and quantity of research evidence available for the treatment of AD with MPACs. To assess any adverse effects and the safety and tolerability of MPACs.

\section{MET HO D S}

\section{Criteria for considering studies for this review}

\section{Types of studies}

For the analysis of treatment effects, all human, unconfounded, randomised double-blind trials in which treatment with an MPAC was administered to participants with Alzheimer's dementia (AD) in a parallel group comparison with placebo were included.

\section{Types of participants}

People with Alzheimer's dementia who fulfil accepted diagnostic criteria such as the Diagnostic and Statistical Manual of Mental Disorders (DSM), International Classification of Diseases (ICD) and the National Institute of Neurological and Communicative Disorders and Stroke and the Alzheimer's Disease and Related Disorders Association (NINCDS-ADRDA) were evaluated (DSM III-R; DSM-IV; McKhann 1984; WHO 1992). 


\section{Types of interventions}

This review considered studies comparing treatment with an MPAC, or preparations in which an MPAC was the principle component, by any route of administration, at any dose and for any duration with a placebo.

\section{Types of outcome measures}

\section{Primary outcomes \\ - Cognitive function (as measured by psychometric tests)}

\section{Secondary outcomes \\ - Clinical global impression \\ - Quality of life \\ - Functional performance \\ - Effect in carer \\ - Biomarkers \\ - Safety and adverse effects \\ - Death}

\section{Search methods for identification of studies}

\section{Electronic searches}

We searched

ALOIS

www.medicine.ox.ac.uk/alois), the Cochrane Dementia and Cognitive Improvement Group Specialized Register on 29 July 2010. The search terms used were: Clioquinol OR PBT1 OR PBT2 OR "metal protein" OR MPACS OR MPAC.

ALOIS is maintained by the Trials Search Co-ordinator of the Cochrane Dementia Group and contains studies in the areas of dementia prevention, dementia treatment and cognitive enhancement in healthy persons. The studies are identified from the following.

1. Monthly searches of a number of major healthcare databases: MEDLINE, EMBASE, CINAHL, PsycINFO and LILIACS.

2. Monthly searches of a number of trial registers: ISRCTN; UMIN (Japan's Trial Register); the WHO portal (which covers ClinicalTrials.gov; ISRCTN; the Chinese Clinical Trials Register; the German Clinical Trials Register; the Iranian Registry of Clinical Trials; the Netherlands National Trials Register, plus others).

3. Quarterly search of the Cochrane Central Register of Controlled Trials (CENTRAL) (The Cochrane Library).

4. Six-monthly searches of a number of grey literature sources: ISI Web of Knowledge Conference Proceedings; Index to Theses; Australasian Digital Theses.
To view a list of all sources searched for ALOIS see About ALOIS on the ALOIS website.

Details of the search strategies used for the retrieval of reports of trials from the healthcare databases, CENTRAL and conference proceedings can be viewed in the 'methods used in reviews' section within the editorial information about the Dementia and Cognitive Improvement Group.

Additional searches were performed in many of the sources listed above to ensure that the search for the review was as up-to-date and as comprehensive as possible. The search strategies used can be seen in Appendix 1.

The latest search (July 2010) retrieved a total of 79 results. After a first assessment and de-duplication of these results the authors were left with seven references to further assess. Of these, three were discussion or comment articles. Two articles were eligible for inclusion in this review (Lannfelt 2008; Ritchie 2003). Two further articles were excluded; one was a secondary analysis of data from Lannfelt 2008 (Faux 2010) and one was an erratum related to Lannfelt 2008. A pre-publication search was completed on 17 January 2012 and no further articles were identified.

\section{Data collection and analysis}

\section{Selection of studies}

Two review authors (RM, ES) independently examined references retrieved by the search strategy in order to discard those which were clearly not eligible for the review. The full text of remaining references was retrieved and the inclusion criteria were applied to these independently by the two review authors.

\section{Quality assessment}

Review authors (RM, LJ, ELS) independently assessed the quality of the trials according to criteria described in the Cochrane Collaboration Handbook (Alderson 2004).

\section{Data extraction}

We extracted data from published reports on to a standard form (Cochrane Dementia and Cognitive Improvement Group template).

For each outcome with continuous data, the summary statistics required for each trial were the mean change from the baseline, the standard error of the mean change, and the number of patients for each treatment group at each assessment. The baseline assessment was defined as the latest available assessment prior to randomisation, no longer than two months prior. Where changes from baseline were not reported, the mean, standard deviation and the number of patients for each treatment group at each time point were extracted, where available. For binary data the numbers in 
each treatment group and the numbers experiencing the outcome of interest were sought.

For each outcome measure, data were sought on every patient randomised. To allow an intention-to-treat analysis, the data were sought irrespective of compliance, whether or not the patient was subsequently deemed ineligible or otherwise excluded from treatment or follow-up. If intention-to-treat data were not available in the publications, the data of those who completed the trial or who were treated throughout according to the protocol ('per protocol') were sought and indicated as such.

\section{Data analysis}

The outcomes measured in clinical trials of dementia and cognitive impairment often arise from ordinal rating scales. Where the rating scales used in the trials had a reasonably large number of categories (more than 10) the data were treated as continuous outcomes arising from a normal distribution. Summary 'change from baseline' statistics (n, mean and standard deviation) were sought for each rating scale at each assessment time, for each treatment group, and in each trial.

When change from baseline results were not reported, we calculated the required summary statistics from the group means and standard deviations at baseline and assessment time. In such cases, we assumed a zero correlation between the measurements at baseline and assessment time. This conservative method overestimates the standard deviation of the change from baseline but is preferable in a meta-analysis.

For continuous outcomes, overall estimates of the treatment differences between the intervention and placebo would have been calculated as the weighted average of the individual study estimates if there had been more than one study.

For binary outcomes, such as clinical improvement or no clinical improvement, we used the odds ratio to measure treatment effect. If there had been more than one study, we would have calculated a weighted estimate of the typical treatment effect across trials. Overall estimates of the treatment difference were presented.
A total of 36 people were recruited who met the protocol criteria of having a diagnosis of probable AD using NINCDS-ADRDA, an ADAS-Cog score of 20 to 45, an MMSE score of between 10 and 24 and having been on donepezil 5 to $10 \mathrm{mg}$ for over six months. The mean age of participants was 73 years. In the clioquinol group $50 \%$ were male compared with $56 \%$ in the placebo group. The mean baseline ADAS-Cog scores were 25.56 and 27.06 in the clioquinol and placebo groups, respectively. The clioquinol and placebo groups did not differ across most demographic, biological and clinical variables at baseline, however the treatment arm had a higher mean pre-morbid IQ than the placebo group as estimated using the National Adult Reading Test (111.4 versus 104.9; $\mathrm{t}_{30 \mathrm{df}}$ $=2.27 ; \mathrm{P}=0.03)$ and a lower level of thyrotropin (1.14 versus 2.00 $\left.\mathrm{mIU} / \mathrm{L} ; \mathrm{t}_{30 d f}=4.40 ; \mathrm{P}<0.001\right)$. For other details of the trial, see the 'Characteristics of included studies' table. Additional data were collected on plasma zinc, copper and Aß levels at four-weekly intervals throughout the study. Further studies of clioquinol (PBT1) were abandoned in favour of a successor compound, PBT2 (Prana 2005).

In the second randomised double-blind, placebo-controlled trial included in this review (Lannfelt 2008), a total of 78 participants were randomised after meeting the entry criteria: an ADAS-Cog score of 10 to 25 and a MMSE score of between 20 and 26 (both scores must have been consistent with early $\mathrm{AD}$ ), were taking a stable dose of acetylcholinesterase inhibitor for at least four months, and met the NINCDS-ADRDA criteria for Alzheimer's dementia. Patients were assigned to receive PBT2 $(50 \mathrm{mg}$ or $250 \mathrm{mg}$ ) or placebo once per day for 12 weeks. The three groups did not differ in terms of demographic characteristics at baseline. The mean age of the study population was 72 years and the baseline ADAS-cog scores were 18.9 in the placebo group and PBT2 $50 \mathrm{mg}$ group and 18.7 in the group who received $250 \mathrm{mg}$ of PBT2. For further details see the table 'Characteristics of included studies'. The principle outcomes were safety and tolerability; the secondary outcomes were cognition and effects on cerebrospinal fluid (CSF) and plasma biomarkers.

\section{Scales}

\section{Alzheimer's Disease Assessment Scale-cognitive section (ADAS-Cog) (Rosen 1984)}

ADAS was designed to measure the severity of the most important symptoms of AD. Its subscale ADAS-Cog is a standard measure to assess change in cognitive function in clinical trials. It consists of 11 tasks measuring the disturbances of memory, language, praxis, attention and other cognitive abilities, which are often referred to as the core symptoms of AD. It is a 70-point scale and patients are given a score on 11 sub-items ranging from 0 to 5, with higher scores suggesting greater impairment. 


\section{Alzheimer's Disease Assessment Scale-non cognitive section (ADAS-NC) (Rosen 1984)}

ADAS was designed to measure the severity of the most important symptoms of AD. This subscale, ADAS-NC, was designed to assess the non-cognitive behavioral dysfunctions characteristic of persons with Alzheimer's dementia. It consists of 10 items and examines moods and behaviours including delusions, hallucinations, changes in appetite and motor behaviours. Scores on each subitem range from 0 to 5 , total scores may range from 0 to 50 , and higher scores suggest greater behavioural or mood disturbances.

\section{Clinician's Interview-Based Impression of Change+ (CIBIC+) (Knopman 1994)}

This is a semi-structured interview performed with the caregiver. It consists of a 7-point Likert scale that assesses change from baseline in terms of the clinician's rating of global function. The scale ranges from 1 ('very much improved') to 7 ('very much worse'), with 4 indicating no change since baseline.

\section{The Neuropsychological Test Battery (NTB) (Harrison 2007)}

The NTB gives nine outcome measures, four of memory: Wechsler Memory Scale Verbal Paired Associates test (immediate and delayed) and the Rey Auditory Verbal Learning Test (immediate and delayed); and five of executive function: Wechsler Memory Digit Span, Controlled Oral Word Association Test, Category Fluency Test and trail making test parts A and B. It has been shown to be reliable to assess changes in patients with mild AD. Data can be analysed at the level of individual item scores, domain scores with comparison of the z-statistic or by a composite (global) score.

\section{Mini-mental State Examination (MMSE) (Folstein 1975)}

The MMSE evaluates cognition in five areas: orientation, immediate recall, attention and calculation, delayed recall, and language. The scores range from 0 (severe impairment) to 30 (normal).

\section{Risk of bias in included studies}

The study of Ritchie 2003 was a double-blind, placebo-controlled, parallel-group randomised design. The statistical analysis was undertaken by independent contractors. The study was reported as a phase 2 pilot clinical trial and there were a number of methodological limitations which must be considered.

The report did not detail the measures taken to implement and protect double-blinding or contain information regarding the method of randomisation or concealment of the treatment allocation (this may have been due to lack of space in the published report). Twenty-nine patients failed the screening; five due to their cognition being too poor, 15 because their cognition was too good, five due to ill health: and four failed the neurological screen. In total, five participants were withdrawn after randomisation, two from the placebo group and three from the active treatment arm. The reasons for withdrawal are described briefly in the study flowchart. The treatment arm had higher mean pre-morbid IQ than the placebo group and a lower level of thyrotropin suggesting an imbalance post-randomisation.

In addition to the stated primary efficacy measure (ADAS-Cog), data were collected on plasma zinc, copper and Aß levels at fourweekly intervals. The discussion and title of the study, however, suggested that the main aim of the study was 'proof of concept' that clioquinol targets $A ß$ metabolism. Despite this, the study was only powered to detect "conspicuous effects" on cognition, thus the interpretation of the results of additional analyses on the effect of clioquinol on plasma zinc, copper and Aß levels should be interpreted with caution. No details of the power calculation were given. As well as analysing the difference in change from baseline between treatment arms, a secondary analysis was performed and the groups stratified by severity. The report explained that this was a 'planned' analysis although this was not stated as being a primary aim of the study. The stratification resulted in small numbers of participants in each group for subsequent analyses (less severely affected group: placebo $n=7$, active treatment $n=8$; more severely affected group: placebo $\mathrm{n}=9$, active treatment $=8$ ).

The study of Lannfelt 2008 was also a double-blind, placebo-controlled, parallel-group randomised design. The statistical analysis was conducted by the study team. Eighty-eight potential study participants were assessed for eligibility and 78 were recruited as they met baseline criteria. Safety measures, plasma biomarkers and cognition on the NTB were assessed at baseline and at weeks 2, 4,8 , and 12 with a follow-up at week 14 . ADAS-Cog and the MMSE were done at screening and at week 12.

Placebo capsules were identical to the PBT2 capsules and the randomisation was conducted by an independent statistician using a computerised random number generator. Patients, carers, study staff and the sponsor were blinded to treatment allocation. Ten individuals failed the initial screening because they did not meet inclusion criteria and a further four participants were withdrawn post-randomisation (one did not meet eligibility criteria, one for taking excluded medication, one due to carer illness, and one due to non-compliance). The authors clearly stated that this was an exploratory study and therefore there was no formal calculation of sample size. Safety and efficacy analyses were done on an intention-to-treat basis. The primary objective was to study safety and tolerability.

\section{Effects of interventions}

\section{PBTI (clioquinol)}


There was one included trial (Ritchie 2003) of clioquinol compared with placebo. Thirty-six patients were recruited and $32 \mathrm{had}$ sufficient data for per protocol analysis.

\section{Primary outcome}

\begin{abstract}
ADAS-Cog
The primary outcome, ADAS-Cog, was subject to two-way analysis of variance with factors of treatment arm. Both the clioquinol and placebo arms showed a decrease (improvement) in ADAS-Cog scores at weeks 24 and 36, a difference in mean change from baseline of 7.37 (95\% confidence interval (CI) 1.51 to 13.24 ) in the clioquinol arm and 6.36 (95\% CI -0.50 to 13.23$)$ in the placebo arm. However, the main effect of the treatment arm was not significant at any time point during the study. The effect of severity of illness was measured by stratification of the sample (using a cutpoint of the median): ADAS-Cog $<25$ (less severely affected) and ADAS-cog $>25$ (more severely affected). This analysis was not pre-specified in the protocol. Significant differences favouring the clioquinol arm were found only at weeks $4(\mathrm{~F} 1,28=7.73$; $\mathrm{P}=$ $0.01)$ and $24(\mathrm{~F} 1,28=6.63 ; \mathrm{P}=0.02)$ on post hoc analysis in the more severely affected patients. Therefore, this may have been a chance finding attributable to multiple comparisons at multiple time points.
\end{abstract}

\section{Secondary outcomes}

\section{MMSE}

The authors stated that analysis of MME scores showed a similar pattern to the ADAS-Cog but no further details were given in the paper.

\section{ADAS-Non cog}

Analysis of these results showed no statistically significant difference between the two groups.

\section{CIBIC}

Analysis of these results showed no statistically significant difference in global function between the two groups.

\section{Plasma biomarkers (Aß42, zinc and copper)}

The authors stated that the plasma Aß42 level declined significantly from baseline in the clioquinol group from week 20 onwards (actual figures for plasma Aß42 not given). This was the opposite for the placebo group, which showed a rise in plasma Aß42 level during the same time period. We do not know what the clinical effect of this was. The total plasma zinc level was described as 'increased' in the clioquinol group at 32 weeks compared to placebo. There was no effect on plasma copper levels. Again, as with the changes noted in plasma Aß42 levels, the underlying mechanisms and clinical implications of this are not known.

\section{Safety and tolerability}

As there is an association of clioquinol with subacute myelopathic neuropathy (SMON), neurological adverse events were of interest. There were a total of 123 attributable adverse events reported, 64 in the treatment group and 59 in the placebo arm. Serious adverse events occurred in two of 16 patients in the treatment group. A 66 year-old woman with a background history of hypertension, hyperlipidaemia, glaucoma and visual migraine developed impaired visual acuity and colour vision in the absence of other neurological signs or symptoms. She was on a dose of $375 \mathrm{mg}$ of clioquinol twice a day. The symptoms resolved on treatment cessation and were thought to be possibly attributable to the drug. Another patient in the treatment arm reported syncope due to impaired cardiac function. Serious adverse events also occurred in three of the 16 in the placebo arm, one death due to intracranial haemorrhage, three hospitalisations due to hip pain and one due to confusion.

\section{PBT2}

There was one included trial (Lannfelt 2008) of PBT2 at doses of $50 \mathrm{mg}$ or $250 \mathrm{mg}$ compared with placebo. Of the 78 patients randomised, all were included in the intention-to-treat analysis.

\section{Primary outcome}

\section{Neuropsychological test battery (NTB)}

There was no significant difference in the NTB composite, memory or executive scores between placebo and PBT2 in the least squares mean change from baseline at week 12 . However, two executive function component tests of the NTB showed significant improvement over placebo in the PBT2 $250 \mathrm{mg}$ group from baseline to week 12 : category fluency test $(2.8$ words, $95 \%$ CI 0.1 to 5.4; $\mathrm{P}=0.041)$ and trail making part B $(-48.0 \mathrm{~s}, 95 \% \mathrm{CI}-83.0$ to $-13.0 ; \mathrm{P}=0.009)$. It should be noted that subsequently an erratum was published describing an error in the reporting of the composite and executive function z-scores for the NTB (Lannfelt 2008 (erratum)). There remained no significant difference in the NTB composite scores between placebo and PBT2 in the least squares mean change from baseline at week 12 . In the executive factor $Z$ score, the difference in least squares mean change from baseline at week 12 for PBT2 $50 \mathrm{mg}$ compared with placebo was 0.18 ( -0.06 to $0.42 ; \mathrm{p}=0 \cdot 137)$ and for PBT2 $250 \mathrm{mg}$ compared with placebo was $0 \cdot 27(0 \cdot 01$ to $0 \cdot 53 ; \mathrm{p}=0 \cdot 042)$. 
A further post hoc analysis of this data (Faux 2010) found that the proportions of patients showing improvement on NTB Composite or Executive Factor z-scores were significantly greater in the PBT2 $250 \mathrm{mg}$ group than in the placebo group. There were no correlations between changes in cerebrospinal fluid (CSF) amyloid- $\beta$ or tau species and cognitive changes.

\section{MMSE}

After 12 weeks there was no significant improvement in MMSE scores in either the PBT $50 \mathrm{mg}$ or $250 \mathrm{mg}$ groups compared to placebo.

\begin{abstract}
ADAS-Cog
After 12 weeks there was no significant improvement in ADASCog scores in either the PBT $50 \mathrm{mg}$ or $250 \mathrm{mg}$ groups compared to placebo.
\end{abstract}

\section{Secondary outcomes}

\section{Safety and tolerability}

Forty-two (54\%) patients had at least one treatment emergent adverse event (10 (50\%) on PBT2 $50 \mathrm{mg}, 18(62 \%)$ on PBT2 250 $\mathrm{mg}$, and 14 (48\%) on placebo). The most common adverse events in the whole study sample were headache, dizziness, somnolence, nasopharyngitis and fatigue. Two patients in the placebo group experienced a serious adverse event (one man had urosepsis and one woman a transient Ischaemic attack). No serious adverse events were reported by patients on PBT2. There were no clinically significant adverse findings on vital signs, biochemical, haematological, urinalysis, neurological, opthalmological, electrocardiograph (ECG) or physical parameters.

Plasma biomarkers (Aß42, Aß40, zinc and copper)

PBT2 had no significant effect on plasma concentrations of Aß42, Aß40, zinc and copper.

CSF biomarkers (Aß42, Aß40, total tau, phosphorylated tau, zinc and copper)

Patients treated with PBT2 $250 \mathrm{mg}$ had a dose-dependent (P $=0.023)$ and significant reduction in CSF Aß42 concentration compared with those treated with placebo: the difference in least squares mean change from baseline was $-56.0 \mathrm{pg} / \mathrm{mL}$ (95\% CI 101.5 to $-11.0 ; \mathrm{P}=0.006)$. PBT2 had no significant effect on CSF $A ß 40$, total tau, phosphorylated tau, zinc or copper.

\section{I S C U SSIO N}

At the beginning of this review we outlined the physiological reasons why MPACs may be useful in the treatment of $\mathrm{AD}$ and set out to look for evidence of efficacy to support this. We identified two randomised placebo controlled trials of MPACs. The first (Ritchie 2003) compared the MPAC clioquinol (PBT1) with placebo. There were no significant difference on the primary outcome measure (cognition) between clioquinol and placebo, or on the secondary outcomes of non-cognitive symptoms (ADAS-NC) or clinical global impression (Clinician's Interview-Based Impression of Change (CIBIC)). We have concerns about the quality of the reporting of the study, in particular the lack of information on randomisation and concealment of treatment allocation. The stratification of the analysis by baseline dementia severity only serves to suggest pre-specified analyses in future studies and is not, at this stage, of clinical relevance. The significant differences between some of the baseline variables highlight the importance of adequate sample size and randomisation, and the risks that such differences can undermine or cause real differences in the outcomes of interest. The study was conducted over 36 weeks; this may not be sufficient time to detect clinically meaningful end points, evidence of modification of the disease course or longer-term adverse events.

The phase IIa trial of a second MPAC (Lannfelt 2008), PBT2, was more rigorous with regards to randomisation, allocation and reporting and analysis of results. The primary outcome was safety and tolerability and the results of this were favourable. Cognition was a secondary outcome and PBT2 did not have a statistically significant effect on ADAS-Cog or MMSE scores, although there was a statistically significant improvement in the executive factor $Z$ score in those treated with the higher dose of PBT2 $(250 \mathrm{mg})$.

\section{AUTHORS' CONCLUSIONS}

\section{Implications for practice}

Clioquinol PBT1 cannot be recommended for clinical use. There is no current evidence for clinical efficacy and the one small study detailed in this review does not include enough participants to draw any conclusions on safety. In a 12 week trial PBT2 appeared to have a favourable safety profile. We do not yet know whether the effects of PBT2 on cognition and biomarkers have clinical significance.

\section{Implications for research}

MPACs potentially offer a novel approach to the treatment of Alzheimer's dementia. In vitro and animal studies suggest they promote the solubilisation and clearance of $A ß$. The clioquinol PBT1 trial did not demonstrate efficacy. However, this phase II trial may have been underpowered to detect an effect on cognition. The results of the phase IIa trial of PBT2 suggest that future, larger phase III trials of longer duration are warranted to demonstrate whether PBT2 has disease modifying effects. In addition to cognition, these should consider other clinically relevant outcomes 
such as non-cognitive behavioural symptoms and clinical global impression. It is important that concerns about neurological side effects of MPACs are balanced with the need to urgently find therapies for Alzheimer's dementia, a progressive neurodegenerative disease for which currently no disease modifying agents are available.

\section{ACKNOWLEDGEMENTS}

The authors wish to thank David Janes for acting as consumer editor.

\section{RE F E R E C E S}

\section{References to studies included in this review}

Lannfelt 2008 \{published data only\}

* Lannfelt L, Blennow K, Zetterberg H, Batsman S, Ames

$\mathrm{D}$, Harrison J, et al.Safety, efficacy and biomarker findings of PBT2 in targeting $\mathrm{A} \beta$ as a modifying therapy for Alzheimer's disease: a phase IIa double-blind randomised placebo-controlled trial. Lancet Neurology 2008;7:779-86.

Ritchie 2003 \{published data only\}

Ritchie CW, Bush AI, Mackinnon A, et al.Metal-protein attenuation with iodo-chlorhroxyquin(clioquinol) targeting $A ß$ amyloid deposition and toxicity in Alzheimer disease:a pilot phase 2 clinical trial. Archives of Neurology 2003;60: 1685-91.

\section{References to studies excluded from this review}

Finefrock 2003 \{published data only\}

Finefrock AE, Bush AI, Doraiswamy PM. Current status of metals as therapeutic targets in Alzheimer's disease. Journal of the American Geriatrics Society 2003;51(8):1143-8.

Mastwyk 2003 \{published data only\}

Mastwyk M, Macfarlane S, LoGiudice D, Sullivan KA. Why participate in an Alzheimer's disease clinical trial? Is it of benefit to carers and patients?. International Psychogeriatrics IPA 2003;15(2):149-56.

Regland 2001 \{published data only\}

Regland B, Lehmann W, Abedini I, Blennow K, Jonsson M, Karlsson I, et al.Treatment of Alzheimer's disease with clioquinol. Dementia and Geriatric Cognitive Disorders 2001;12(6):408-14.

\section{Additional references}

\section{Adlard 2008}

Adlard PA, Cherny RA, Finkelstein DI, et al.Rapid restoration of cognition in Alzheimer's transgenic mice with 8-hydroxyquinolone analogs is associated with decreased interstitial Aß. Neuron 2008;59:43-55.
Alderson 2004

Higgins JPT, Green S, editors. Cochrane Handbook for Systematic Reviews of Interventions 5.1.0 [updated March 2011]. The Cochrane Library. John Wiley \& Sons, Ltd, 2011, issue 1:Chapter 8.

Atwood 2002

Attwood CS, Martins RN, Smith MA, Perry G. Senile plaque composition and posttranslational modification of amyloid-beta peptide and associated proteins. Peptides 2002;23:1343-50.

Brookmeyer 1998

Brookmeyer R, Gray S, Kawas C. Projections of Alzheimer's disease in the United States and the public health impact of delaying disease onset. American Journal of Public Health 1998;88:1337-42.

Bush 1994

Bush AI, Pettingell WH, Maulthaup G, et al.Rapid induction of Alzheimer $A ß$ amyloid formation by zinc. Science 1994;265:1464-7.

Bush 2003

Bush AI. The metallobiology of Alzheimer's disease. Trends Neuroscience 2003;26:207-14.

\section{Cherny 2001}

Cherny RA, Atwood CS, Xilianas ME, et al.Treatment with copper-zinc chelator markedly and rapidly inhibits ß-amyloid accumulation in Alzheimer's disease transgenic mice. Neuron 2001;30:665-76.

\section{DSM III-R}

American Psychiatric Association. Diagnostic and Statistical Manual of Mental Disorders. 3th revised. Washington, DC: American Psychiatric Association, 1987.

\section{DSM-IV}

American Psychiatric Association. Diagnostic and Statistical Manual of Mental Disorders. 4th Edition. Washington, DC: American Psychiatric Association, 1994. 


\section{Faux 2010}

Faux NG, Ritchie CW, Gunn A, et al.PBT2 rapidly improves cognition in Alzheimer's disease: additional phase II analyses. Journal of Alzheimers Disease 2010;20(2): 509-16.

Folstein 1975

Folstein MF, Folstein SE, McHugh PR. Mini-mental state: a practical method for grading the cognitive state of patients for the clinician. Journal of Psychiatry Research 1975;12: 189-98.

\section{Harrison 2007}

Harrison J, Minassian SL, Jenkins L, et al.A neuropsychological test battery for use in Alzheimer disease clinical trials. Archives of Neurology 2007;64:1323-9.

Knopman 1994

Knopman DS, Knapp MJ, Gracon SI, Davis, CS. The Clinician Interview-Based Impression (CIBI): A clinician's global change rating scale in Alzheimer's disease. Neurology 1994; 44:2315.

Lannfelt 2008 (erratum)

Lannfelt L, Blennow K, Zetterberg H, Batsman S, Ames D, Harrison J, et al.Safety, efficacy, and biomarker findings of PBT2 in targeting Abeta as a modifying therapy for Alzheimer's disease: a phase IIa, double-blind, randomised, placebo-controlled trial. (Erratum). Lancet Neurology 2009; 8(11):981.

\section{McKhann 1984}

McKhann G, Drachman D, Folstein M, Katzman R, Price D, Stadlan EM. Clinical diagnosis of Alzheimer's disease: report of the NINCDS-ADRDA Work Group under the auspices of Department of Health and Human Services Task Force on Alzheimer's Disease. Neurology 1994;34:939-44.

Prana 2005

Prana Completes Review of Development Programme. http://www.pranabio.com/downloads/Media\%20Releases/
2005\%2016\%20June\%20Prana\%20Completes\%20Review\%20of\%20Development 16th June 2005.

\section{Rosen 1984}

Rosen WG, Mohs RC, Davis KL. A new rating scale for Alzheimer's disease. American Journal of Psychiatry 1984;11: 1356-64.

\section{WHO 1992}

World Health Organization. The ICD-10 classification of mental and behavioural disorders: clinical description and diagnostic guidelines. Geneva: World Health Organization, Division of Mental Health, 1992.

\section{Wirths 2004}

Wirths O, Multhaup G, Bayer TA. A modified beta-amyloid hypothesis: intraneuronal accumulation of the beta-amyloid peptide-the first step of a fatal cascade. Neurochemistry 2004:91:513-20.

Yassin 2000

Yassin MS, Ekblom J, Xilinas M, Gottfries CG, Oreland L. Changes in uptake of vitamin B12 and trace metals in brains of mice treated with clioquinol. Journal of Neurological Science 2000;173:40-4.

\section{References to other published versions of this review}

\section{Jenagaratnam 2006}

Jenagaratnam L, McShane R. Clioquinol for the treatment of Alzheimer's disease. Cochrane Database of Systematic Reviews 2006, Issue 1.

\section{Sampson 2008}

Sampson E, Jenagaratnam L, McShane R. Metal protein attenuating compounds for the treatment of Alzheimer's disease. Cochrane Database of Systematic Reviews 2008, Issue

* Indicates the major publication for the study 


\section{CHARACTERISTICS OF STUDIES}

\section{Characteristics of included studies [ordered by study ID]}

\section{Lannfelt 2008}

\begin{tabular}{|c|c|}
\hline Methods & $\begin{array}{l}\text { Allocation: randomisation } \\
\text { Blindness: double blind } \\
\text { Duration: } 12 \text { weeks }\end{array}$ \\
\hline Participants & $\begin{array}{l}\text { Diagnosis: Early Alzheimer's dementia. } \mathrm{N}=78 \\
\text { Age: Mean 72, range 58-83 years } \\
\text { Sex: F39, M39 } \\
\text { Setting: Multicentre (Sweden } 8 \text { centres, Australia } 7 \text { centres) } \\
\text { Inclusion: NINCDS-ADRDA criteria for Alzheimer's dementia, Adas-Cog score of 10- } \\
\text { 25, MMSE score of between } 20 \text { and 26, taking a stable dose of acetylcholinesterase } \\
\text { inhibitor for at least } 4 \text { months, modified Hachinski score of } 4 \text { points or less, CT or MRI } \\
\text { scan consistent with Alzheimer's dementia }\end{array}$ \\
\hline Interventions & PBT2 $(50 \mathrm{mg}$ or $250 \mathrm{mg}$ ) or placebo once per day for 12 weeks \\
\hline Outcomes & $\begin{array}{l}\text { Primary outcome: safety and tolerability } \\
\text { Secondary outcomes: NTB at baseline, } 2,4,8,12 \text { and } 14 \text { weeks } \\
\text { Adas-Cog and MMSE at baseline and } 12 \text { weeks }\end{array}$ \\
\hline Notes & $\begin{array}{l}\text { Plasma biomarkers (A } \beta 42, \mathrm{~A} \beta 40 \text {, zinc and copper, baseline, } 2,4,8,12 \text { and } 14 \text { weeks). } \\
\text { CSF biomarkers ( } \mathrm{A} \beta 42, \mathrm{~A} \beta 40 \text {, total tau, phosphorylated tau, zinc and copper, baseline } \\
\text { and week 12) }\end{array}$ \\
\hline
\end{tabular}

\section{Risk of bias}

\begin{tabular}{l|l|l}
\hline Bias & Authors' judgement & Support for judgement \\
\hline $\begin{array}{l}\text { Random sequence generation (selection } \\
\text { bias) }\end{array}$ & Low risk & $\begin{array}{l}\text { Randomised by computer random number } \\
\text { generation }\end{array}$ \\
\hline Allocation concealment (selection bias) & Low risk & $\begin{array}{l}\text { Placebo capsules were identical to PBT2 } \\
\text { capsules }\end{array}$ \\
\hline
\end{tabular}

Blinding of participants and personnel Low risk

Study is described as double blind (performance bias)

All outcomes

\begin{tabular}{l|l|l}
\hline $\begin{array}{l}\text { Blinding of outcome assessment (detection } \\
\text { bias) }\end{array}$ & Low risk & Study is described as double blind \\
All outcomes & & \\
\hline
\end{tabular}

\begin{tabular}{|c|c|c|}
\hline $\begin{array}{l}\text { Incomplete outcome data (attrition bias) } \\
\text { All outcomes }\end{array}$ & Low risk & Used intention-to-treat analysis \\
\hline
\end{tabular}


Lannfelt 2008 (Continued)

Selective reporting (reporting bias) High risk

Selection and reporting of individual items from a test battery

Ritchie 2003

\begin{tabular}{|c|c|}
\hline Methods & $\begin{array}{l}\text { Allocation: randomisation } \\
\text { Blindness: double blind } \\
\text { Duration: } 36 \text { weeks }\end{array}$ \\
\hline Participants & $\begin{array}{l}\text { Diagnosis: Alzheimer's dementia. } \mathrm{N}=36 \\
\text { Age: Mean } 72.5 \text {, SD } 8.4 \text {, range } 56-87 \text { years } \\
\text { Sex: F 15, M } 17 \\
\text { Setting:Australia } \\
\text { Inclusion: diagnosis of probable AD using NINCDS-ADRDA, an ADAS-Cog score of } \\
\text { 20-45, an MMSE score of between 10-24 and having been on donepezil 5-10 mg for } \\
\text { over six months }\end{array}$ \\
\hline Interventions & $\begin{array}{l}\text { Clioquinol started at } 125 \mathrm{mg} \text { twice daily from weeks } 1 \text { to } 12,250 \mathrm{mg} \text { daily from weeks } \\
13 \text { to } 24 \text {, and } 375 \mathrm{mg} \text { twice daily from weeks } 25 \text { to } 36\end{array}$ \\
\hline Outcomes & $\begin{array}{l}\text { Primary outcome: change from the baseline ADAS-Cog at weeks 4, 12, } 24 \text { and } 36 \\
\text { Secondary outcomes: ADAS-NC, MMSE, CIBIC Plasma Aß, zinc and copper levels }\end{array}$ \\
\hline Notes & Plasma Aß, zinc, and copper levels were measured every 4 weeks \\
\hline
\end{tabular}

Risk of bias

\begin{tabular}{l|l|l}
\hline Bias & Authors' judgement & Support for judgement \\
\hline $\begin{array}{l}\text { Random sequence generation (selection } \\
\text { bias) }\end{array}$ & Unclear risk & Details not given in the paper \\
\hline $\begin{array}{l}\text { Allocation concealment (selection bias) } \\
\text { Blinding of participants and personnel } \\
\text { (performance bias) } \\
\text { All outcomes }\end{array}$ & Low risk & Details not given in the paper \\
\hline $\begin{array}{l}\text { Blinding of outcome assessment (detection } \\
\text { bias) } \\
\text { All outcomes }\end{array}$ & Low risk & Study is described as double blind \\
\hline $\begin{array}{l}\text { Incomplete outcome data (attrition bias) } \\
\text { All outcomes }\end{array}$ & Unclear risk & Study is described as double blind \\
\hline \begin{tabular}{l} 
Selective reporting (reporting bias) \\
\hline
\end{tabular} & High risk & $\begin{array}{l}\text { No information given on subjects who did } \\
\text { not complete the trial }\end{array}$ \\
\hline
\end{tabular}

Metal protein attenuating compounds for the treatment of Alzheimer's dementia (Review) 
Characteristics of excluded studies [ordered by study ID]

\begin{tabular}{ll}
\hline Study & Reason for exclusion \\
\hline Finefrock 2003 & Not a clinical trial \\
\hline Mastwyk 2003 & Not a clinical trial \\
\hline Regland 2001 & Randomised controlled trial but not placebo controlled \\
\hline
\end{tabular}


DATA ANDANALYSES

Comparison 1. Change ADAS-Cog after 36 weeks clioquinol or placebo

\begin{tabular}{lcccc} 
Outcome or subgroup title & $\begin{array}{c}\text { No. of } \\
\text { studies }\end{array}$ & $\begin{array}{c}\text { No. of } \\
\text { participants }\end{array}$ & Statistical method & Effect size \\
\hline $\begin{array}{l}\text { 1 Change in ADASCog at } 36 \\
\text { weeks }\end{array}$ & 1 & 32 & Mean Difference (IV, Fixed, 95\% CI) & $-2.67[-11.60,6.26]$ \\
\hline
\end{tabular}

\section{Analysis I.I. Comparison I Change ADAS-Cog after 36 weeks clioquinol or placebo, Outcome I Change in} ADASCog at 36 weeks.

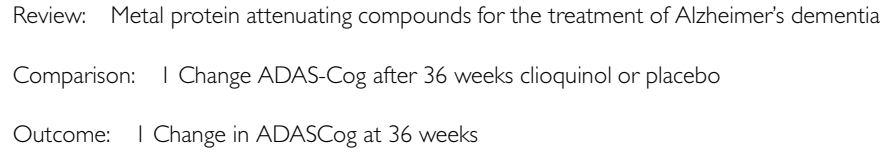

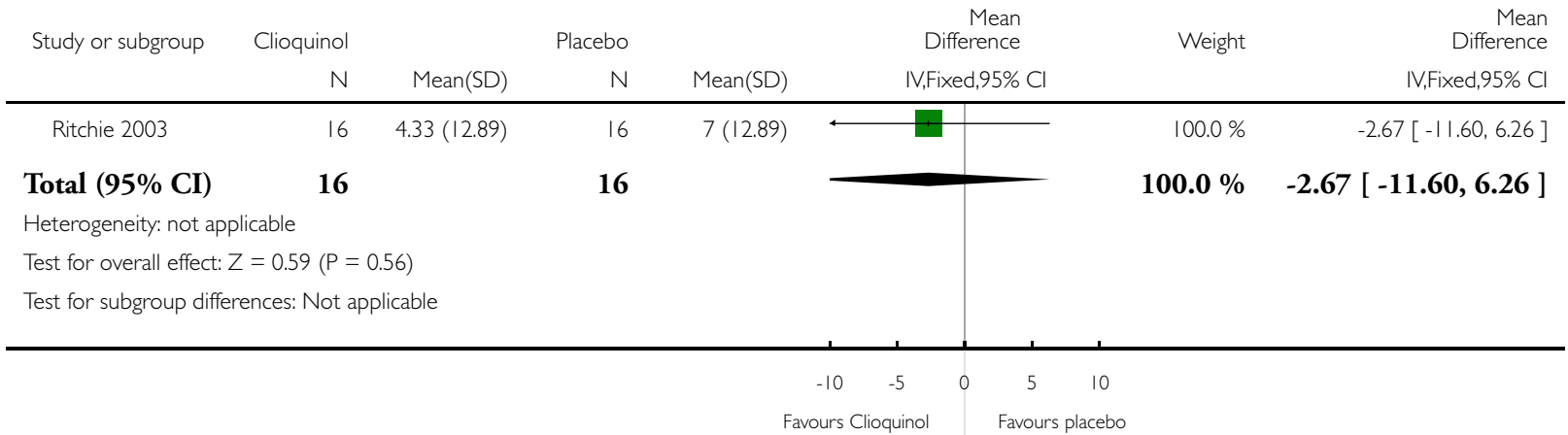


A P P E N D I CES

Appendix I. Update search: July 2010

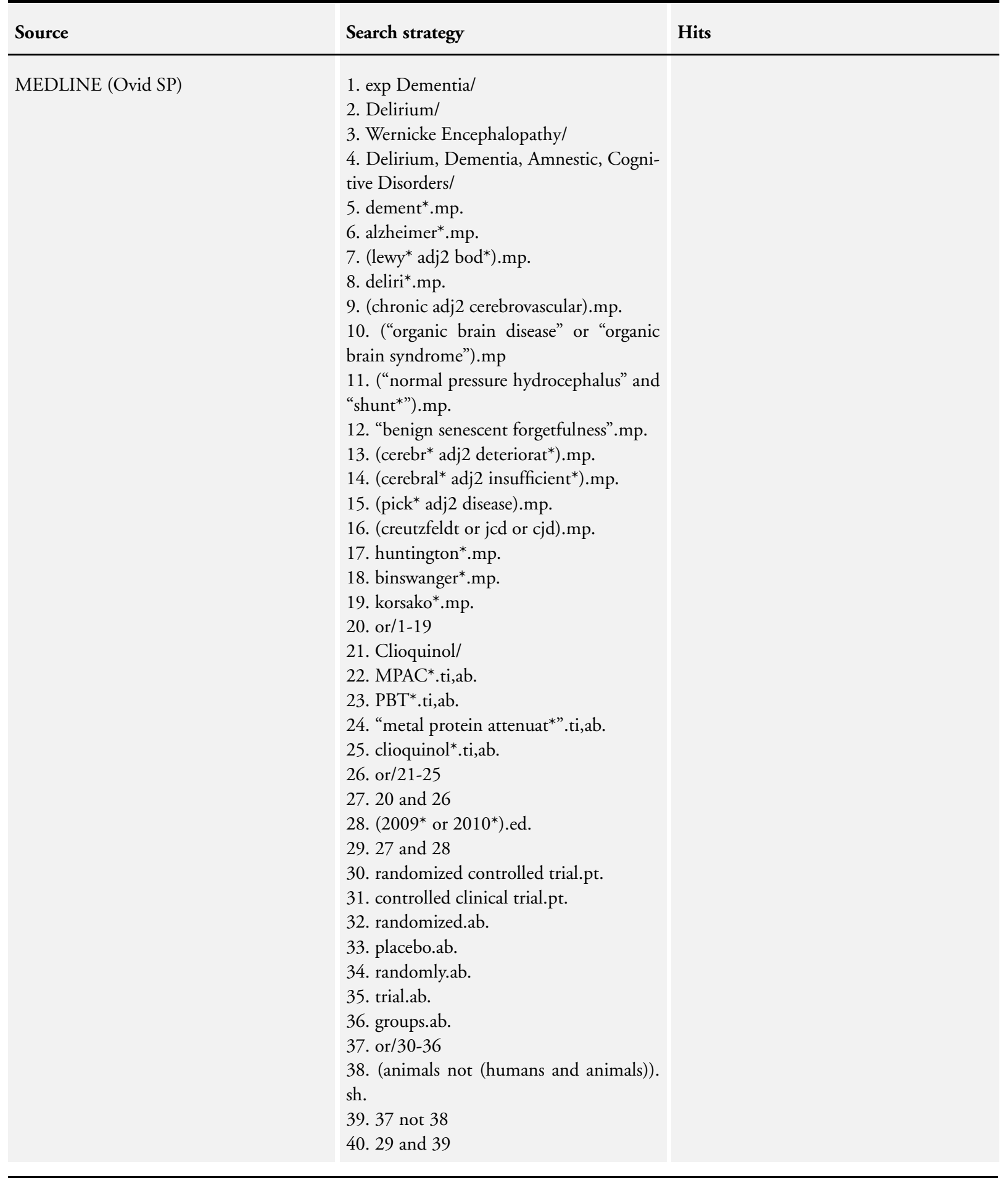

Metal protein attenuating compounds for the treatment of Alzheimer's dementia (Review)

Copyright @ 2014 The Cochrane Collaboration. Published by John Wiley \& Sons, Ltd. 
EMBASE (Ovid SP)
1. exp dementia/

2. Lewy body/

3. delirium/

4. Wernicke encephalopathy/

5. cognitive defect/

6. dement*.mp.

7. alzheimer*.mp.

8. (lewy* adj2 bod*).mp.

9. deliri*.mp.

10. (chronic adj2 cerebrovascular).mp.

11. ("organic brain disease" or "organic brain syndrome").mp

12. "supranuclear palsy".mp.

13. ("normal pressure hydrocephalus" and "shunt").mp.

14. "benign senescent forgetfulness".mp.

15. (cerebr ${ }^{*}$ adj2 2 deteriorat ${ }^{*}$ ).mp.

16. (cerebral ${ }^{*}$ adj2 insufficient $\left.{ }^{*}\right)$.mp.

17. (pick* adj2 disease).mp.

18. (creutzfeldt or jcd or cjd).mp.

19. huntington*.mp.

20. binswanger*.mp.

21. korsako*.mp.

22. CADASIL.mp.

23. or/1-22

24. clioquinol/

25. MPAC*.ti,ab.

26. PBT*.ti,ab.

27. "metal protein attenuat". ti,ab.

28. clioquinol*.ti,ab.

29. or $/ 24-28$

30. 23 and 29

31. $\left(2009^{*}\right.$ or $\left.2010^{*}\right)$.em.

32. 30 and 31

33. randomized controlled trial/

34. controlled clinical trial/

35. randomi?ed.ab.

36. placebo.ab.

37. randomly.ab.

38. trial.ab.

39. groups.ab.

40. or/33-39

41.32 and 40 
6. exp Cognitive Impairment/

7. dement*.mp.

8. alzheimer*.mp.

9. (lewy* adj 2 bod*).mp.

10. deliri*.mp.

11. (chronic adj2 cerebrovascular).mp.

12. ("organic brain disease" or "organic brain syndrome”).mp

13. "supranuclear palsy".mp.

14. ("normal pressure hydrocephalus" and “shunt").mp.

15. "benign senescent forgetfulness".mp.

16. (cerebr* adj2 deteriorat ${ }^{*}$ ).mp.

17. (cerebral* adj2 insufficient $\left.{ }^{*}\right)$.mp.

18. (pick* adj2 disease).mp.

19. (creutzfeldt or jcd or cjd).mp.

20. huntington*.mp.

21. binswanger*.mp.

22. korsako*.mp.

23. ("parkinson* disease dementia" or PDD

or "parkinson* dementia").mp

24. or/1-23

25. clioquinol*.mp.

26. MPAC* ti,ab.

27. PBT* $^{*}$ ti,ab.

28. "metal protein attenuat*”.ti,ab.

29. or $/ 25-28$

30. 24 and 29

31. $\left(2009^{*}\right.$ or $\left.2010^{*}\right)$.up.

32.30 and 31

CINAHL (EBSCOhost)

S1 (MH "Dementia+")

S2 (MH "Delirium") or (MH "Delirium, Dementia, Amnestic, Cognitive Disorders")

S3 (MH "Wernicke's Encephalopathy")

S4 TX dement*

S5 TX alzheimer*

S6 TX lewy* N2 bod*

S7 TX deliri*

S8 TX chronic N2 cerebrovascular

S9 TX "organic brain disease" or "organic brain syndrome"

S10 TX "normal pressure hydrocephalus" and "shunt"

S11 TX "benign senescent forgetfulness"

S12 TX cerebr* N2 deteriorat*

S13 TX cerebral* N2 insufficient*

S14 TX pick* N2 disease

Metal protein attenuating compounds for the treatment of Alzheimer's dementia (Review) 
S15 TX creutzfeldt or jcd or cjd

S16 TX huntington*

S17 TX binswanger*

S18 TX korsako*

$\mathrm{S} 19 \mathrm{~S} 1$ or $\mathrm{S} 2$ or $\mathrm{S} 3$ or $\mathrm{S} 4$ or $\mathrm{S} 5$ or $\mathrm{S} 6$ or $\mathrm{S} 7$

or $S 8$ or $S 9$ or $S 10$ or $S 11$ or $S 12$ or $S 13$ or

$S 14$ or $S 15$ or $S 16$ or $S 17$ or $S 18$

S20 TX clioquinol

S21 MPAC*

S22 PBT*

S23 TX "metal protein attenuat"

S24 S20 or S21 or S22 or S23

S25 S19 and S24

CENTRAL (The Cochrane Library)

\#1 MeSH descriptor Dementia explode all trees

\#2 $\mathrm{MeSH}$ descriptor Delirium, this term only

\#3 MeSH descriptor Wernicke Encephalopathy, this term only

\#4 MeSH descriptor Delirium, Dementia, Amnestic, Cognitive Disorders, this term only

\#5 dement*

\#6 alzheimer*

\#7 "lewy* bod*"

\#8 deliri*

\#9 “chronic cerebrovascular"

\#10 "organic brain disease" or "organic brain syndrome"

\#11 "normal pressure hydrocephalus" and "shunt"

\#12 "benign senescent forgetfulness"

\#13 "cerebr* deteriorat*"

\#14 "cerebral* insufficient*"

\#15 "pick* disease"

\#16 creutzfeldt or jcd or cjd

\#17 huntington*

\#18 binswanger*

\#19 korsako*

\#20 (\#1 OR \#2 OR \#3 OR \#4 OR \#5 OR \#6 OR \#7 OR \#8 OR \#9 OR \#10 OR \# 11 OR \#12 OR \#13 OR \#14 OR \#15 OR \#16 OR \#17 OR \#18 OR \#19)

\#21 clioquinol OR PBT1 OR PBT2 OR

"metal protein*"

\#22 (\#20 AND \#21) 
(Continued)

\begin{tabular}{l|l}
\hline ALOIS (www.medicine.ox.ac.uk/alois) & $\begin{array}{l}\text { Keyword search: Clioquinol OR PBT1 OR } \\
\text { PBT2 OR “metal protein" OR MPACS } \\
\text { OR MPAC }\end{array}$ \\
\hline ClinicalTrials.gov & $\begin{array}{l}\text { (Clioquinol OR PBT1 OR PBT2 OR } \\
\text { metal protein) AND (Alzheimer OR } \\
\text { alzheimers OR alzheimer's OR dementia) }\end{array}$ \\
\hline ICTRP (The WHO portal) & $\begin{array}{l}\text { Clioquinol OR PBT1 OR PBT2 OR metal } \\
\text { protein }\end{array}$ \\
\hline LILACS (BIREME) & $\begin{array}{l}\text { clioquinol AND OR AND PBT1 AND } \\
\text { OR AND PBT2 AND OR AND “metal } \\
\text { AND protein\$” AND OR AND MPAC\$ }\end{array}$ \\
\hline $\begin{array}{l}\text { Web of Science and Conference Proceed- } \\
\text { ings (Web of Knowledge) }\end{array}$ & $\begin{array}{l}\text { Topic=(Clioquinol } \\
\text { OR PBT1 OR PBT2 OR “metal protein”) } \\
\text { AND Topic=(alzheimer* OR dement*) } \\
\text { Timespan=2009-2010. Databases=SCI- } \\
\text { EXPANDED, SSCI, CPCI-S }\end{array}$ \\
\hline
\end{tabular}

\section{WHAT'S NEW}

Last assessed as up-to-date: 9 February 2012.

\begin{tabular}{l|l|l}
\hline Date & Event & Description \\
\hline 20 February 2014 & $\begin{array}{l}\text { New citation required but conclusions have not } \\
\text { changed }\end{array}$ & $\begin{array}{l}\text { Abstract amended to reflect correction of Lannfelt 2008 } \\
\text { trial data }\end{array}$ \\
\hline 20 February 2014 & Amended & Abstract amended \\
\hline
\end{tabular}

\section{H I S T O R Y}

Protocol first published: Issue 3, 2005

Review first published: Issue 1, 2006 


\begin{tabular}{ll|l}
\hline Date & Event & Description \\
\hline 5 September 2012 & Amended & Correction of Lannfelt 2008 trial data \\
\hline 9 February 2012 & New citation required and conclusions have changed & Review updated February 2012 \\
\hline 9 February 2012 & New citation required and conclusions have changed & $\begin{array}{l}\text { Update June 2007 } \\
\text { The literature search undertaken in May 2005 was up- } \\
\text { dated in February 2007. Since the original Cochrane } \\
\text { review was published in 2006, Prana Biotechnology has } \\
\text { suspended PBT1 development. }\end{array}$ \\
\hline 5 November 2008 & Amended & $\begin{array}{l}\text { PBT2, a successor compound to PBT1 for Alzheimer's } \\
\text { disease began a Phase I human clinical trial in March } \\
\text { 2005. Data from this trial were published in 2008 and } \\
\text { these have been included in this review }\end{array}$ \\
\hline
\end{tabular}

\section{CONTRIBUTIONSOFAUTHORS}

LJ: all correspondence; drafting of review versions, selection of trials, extraction of data; entry of data and interpretation of data analysis RM: drafting of review versions, selection of trials, extraction of data and interpretation of data analysis

ELS: update of review April 2007 and February 2012

The searches were carried out by Dymphna Hermans and Anna Noel-Storr

Contact Editor:

Consumer Editor: David Janes

\section{DECLARATIONSOF INTEREST}

LJ and RM declare they have no potential conflicts of interest.

ELS attended a preliminary investigators' meeting for the planned phase III trial of clioquinol that was subsequently abandoned. 


\section{SOURCES OF SUPPORT}

\section{Internal sources}

- Oxfordshire Mental Healthcare Trust, UK.

- Barnet Enfield and Haringey Mental Health Trust, UK.

- Mental Health Sciences Unit, University College London, UK.

\section{External sources}

- No sources of support supplied

\section{NDEX TERMS}

\section{Medical Subject Headings (MeSH)}

Alzheimer Disease [*drug therapy]; Amyloid beta-Peptides [metabolism]; Chelating Agents [adverse effects; *therapeutic use]; Clioquinol [adverse effects; analogs $\&$ derivatives; ${ }^{*}$ therapeutic use]; Randomized Controlled Trials as Topic

\section{MeSH check words}

Aged; Humans 